\title{
A TEORIA DA JUSTIÇA DE JOHN RAWLS E A RESPONSABILIDADE CIVIL
}

\section{RAWLSIAN THEORY OF JUSTICE AND TORT LAW}




\title{
A TEORIA DA JUSTIÇA DE JOHN RAWLS E A RESPONSABILIDADE CIVIL ${ }^{1}$
}

\author{
RAWLSIAN THEORY OF JUSTICE AND TORT LAW
}

\author{
João Vitor Penna ${ }^{2}$ \\ Gabriel Santos Lima ${ }^{3}$
}

\section{RESUMO}

O presente trabalho tem por objetivo apresentar o modo como a concepção de justiça de John Rawls foi importada para a Filosofia da Responsabilidade Civil, a partir das teorias contratualistas de George P. Fletcher e, principalmente, de Gregory C. Keating. O trabalho inicia com uma contextualização histórica da disciplina filosófica do Direito de Danos, demonstrando como Rawls, ao revigorar o conceito de justiça, deu um novo vigor para o caminho de fundamentação da Responsabilidade Civil com base na noção de justiça. Em seguida, expõe-se alguns aspectos importantes da teoria da justiça de Rawls para, assim, analisar as teorias contratualistas, expondo suas teses centrais e em quais pontos elas se apropriam da teoria rawlsiana.

Palavras-chave: John Rawls; Responsabilidade Civil, Filosofia; Justiça.

\section{INTRODUÇÃO}

O estudo dos fundamentos e do conceito de Responsabilidade Civil - ou, como também podemos chamar, Direito de $\operatorname{Danos}^{4}$-, conhecido no contexto anglo-saxão como Filosofia da Responsabilidade Civil (Philosophy of Tort Law), é recente. Cresceu e se destacou como disciplina de pesquisa apenas no século XX, ganhando força em um

\footnotetext{
1 Data de Recebimento: 09/11/2020. Data de Aceite: 23/11/2020.

2 Mestre em Direito pela Universidade Federal do Pará (UFPA). Bacharel em Direito pela mesma Universidade. Membro do Instituto Brasileiro de Estudos de Responsabilidade Civil - IBERC. Conselheiro e Membro fundador da Liga Acadêmica Jurídica do Pará - LAJUPA. Professor da Faculdade FACI (Belém, PA). Advogado. E-mail: jvitorpenna@gmail.com. Currículo Lattes: http://lattes.cnpq.br/7222995294627660. ORCID: https://orcid.org/0000-0003-3098-7793.

3 Bacharel em Direito pela Universidade Federal do Pará (UFPA). Advogado. E-mail: gabrielsantoslima@live.com. Currículo Lattes: http://lattes.cnpq.br/6641506142203659. ORCID: https://orcid.org/0000-0001-5117-5781.

4 Para fins deste trabalho, consideraremos "Responsabilidade Civil" e "Direito de Danos" como sinônimos, que equivalem à disciplina jurídica que lida com as compensações relacionadas à danos, ou seja, com as indenizações.
} 
espaço em que a Responsabilidade Civil também se tornou proeminente diante da complexificação da sociedade.

No Brasil, os estudos sobre Responsabilidade Civil cresçam a cada dia e é lugar comum entender que o instituto é um dos principais instrumentos jurídicos para concretização dos direitos fundamentais. Teses novas envolvem ampliação do sistema de responsabilidade objetiva, desenvolvimento de novos tipos de dano, defensa de indenizações de caráter meramente punitiva, flexibilização dos nexos de causalidade, entre outras questões, surgem constantemente no debate acadêmico. Todas essas propostas possuem um pano de fundo - que inevitavelmente envolve discussões de Filosofia Política e Jurídica - que dificilmente é abordado de maneira adequada.

O contexto de desenvolvimento da Filosofia da Responsabilidade Civil, assim como qualquer outro ramo da Filosofia do Direito aplicada, é totalmente incipiente no Brasil ${ }^{5}$. Aliás, uma breve pesquisa sobre o tema nos permite perceber que há um crescimento significativo das pesquisas em Análise Econômica do Direito aplicada às mais diversas áreas, inclusive à Responsabilidade Civil. Assim, pesquisa filosófica sobre os fundamentos teóricos do Direito de Danos é pendente para apenas um lado da discussão. Estão quase que totalmente esquecidas as teorias que buscam basear a Responsabilidade Civil em uma ideia de justiça, o que é extremamente curioso em um país onde as ideias de Justiça Social ganham tanta força e onde filósofos como John Rawls tem especial relevância dentro da academia. Os privatistas certamente ainda têm muito o que aprender com os publicistas.

Devemos, portanto, voltar nossos estudos para os teóricos anglo-saxônicos para começar a dar passos maiores para uma fundamentação da Responsabilidade Civil Extracontratual. Atentaremos exatamente para o ponto de virada, aquele em que os filósofos do Direito de Danos passaram a se opor à fundamentação econômica e propuseram uma teoria baseada na Justiça. É possível dizer que, de forma indireta, Rawls contribuiu com o desenvolvimento dessas teorias, como tentaremos mostrar ao longo do texto.

Este trabalho é uma análise das interações entre a análise conceitual da Responsabilidade Civil com as Teorias da Justiça, com especial atenção à apropriação da teoria de John Rawls na fundamentação da Responsabilidade Civil. Em sua primeira parte, realizaremos uma introdução à temática, expondo historicamente como a disciplina se desenvolveu, para entender qual o papel indireto Rawls teve na formação de uma corrente específica de fundamentação, a teoria contratualista da Responsabilidade Civil. A segunda parte do trabalho será dedicada alguns aspectos relevantes da teoria rawlsiana que de alguma forma influenciaram a fundamentação da Responsabilidade Civil. Por

5 Não existem textos que visem apresentar e situar o debate em torno da matéria de forma inteligível. Uma exceção interessante a este contexto é o excelente trabalho de Rafael Valle Dresch. Vide DRESCH, 2013. 
fim, em sua terceira parte, apresentaremos a teorias contratualistas do Direito de Danos com foco nas teorias de George P. Fletcher e Gregory C. Keating, seu principal representante, apresentando suas propostas teóricas e tentando demonstrar até que ponto se apropriam da teoria de Rawls em seu empreendimento.

\section{A FILOSOFIA DA RESPONSABILIDADE CIVIL}

A explicação teórica da Responsabilidade Civil não era um problema para os estudiosos do Direito até meados do século XX. As compensações por danos eram, em um certo nível, facilmente explicadas a partir de uma diferenciação entre Justiça Distributiva e Justiça Corretiva (ou Comutativa) que remetia à Aristóteles. Neste esquema, existem dois tipos de Justiça. A Justiça Distributiva se preocuparia com a distribuição dos bens e dos encargos sociais entre os membros da comunidade, enquanto a Justiça Corretiva se encarregaria da retificação dos injustos que surgem tanto nas transações voluntárias (relacionadas ao intercâmbio de bens, como em um contrato), quanto nas involuntárias (relacionadas ao dano, roubo, difamação, etc.). A Responsabilidade Civil seria, assim, uma forma de concretizar a Justiça Corretiva.

Com a complexificação de determinadas relações sociais, com o desenvolvimento industrial, com a intervenção do Estado na economia, entre outros fatores, as concepções clássicas foram postas em cheque e novos problemas foram postos. A medida que novas soluções eram dadas, o modelo clássico de fundamentação se mostrava insuficiente, o que abria espaço para novas propostas. Foi neste contexto que surgiram os estudos que relacionavam Filosofia com a Responsabilidade Civil, nos quais o marco teórico foram os estudos de H. L. A. Hart e Tony Honoré sobre causalidade.

Este período, porém, coincidiu com o crescimento, no contexto anglo-saxônico, de um movimento teórico - que não se restringia à Responsabilidade Civil, mas buscava dar conta da análise do direito como um todo - que buscava mistura ferramentas de microeconomia com uma ética de tipo utilitarista. Era a Análise Econômica do Direito, que encontrou em autores como Guido Calabresi, Richard Posner, Steven Shavell e Louis Kaplow seus grandes representantes.

Em contraposição à estas teorias econômicas de fundamentação do Direito de Danos, se desenvolveram teorias baseadas na ideia de justiça. Os marcos teóricos para esta vertente teórica foram os importantes artigos Fairness and Utility in Tort Theory de George P. Fletcher (FLETCHER, 1972) e A Theory of Strict Liability de Richard Epstein, publicados em 1972 e 1973 respectivamente. Ambos buscavam apresentar o Direito de Danos com base em determinadas concepções de justiça que estavam em intensa discussão à época. O primeiro desenvolvia uma teoria que mesclava as ideias de jus- 
tiça corretiva e distributiva com fundamento no liberalismo igualitário de John Rawls, como veremos adiante. O segundo apresentava uma justificação da Responsabilidade Objetiva com base numa ideia libertária de justiça. Estes dois trabalhos deram início à uma longa tradição que passou a recuperar a noção de justiça corretiva na fundamentação da Responsabilidade Civil por danos, em que se notabilizaram autores como Jules Coleman e Ernest Weinrib.

Dado este panorama do debate, podemos voltar ao objeto deste estudo e verificar como Rawls influenciou no desenvolvimento deste quadro teórico. Antes de mostrar como Rawls influenciou na formação da corrente contratualista de fundamentação do Direito de Danos, existe pelo menos um aspecto importante que a publicação de "Uma Teoria da Justiça" proporcionou. Talvez uma das maiores virtudes de Rawls foi ter conseguido reacender a discussão sobre a justiça, como algo que se pode discutir racionalmente, sem recorrer a questões metafísicas. Se atualmente a principal corrente de fundamentação da Responsabilidade Civil é aquela que se baseia na ideia de justiça, não há dúvidas de que isto só foi possível após se recuperar a ideia de justiça da metafísica e da ética utilitarista.

Sobre esta última, Rawls também tem um papel importante. Como forte opositor do Utilitarismo, é de se imaginar que ele fosse imediatamente adotado para o campo da Responsabilidade Civil para se contrapor ao tipo de teoria que tem como base a ética utilitarista, como a Análise Econômica do Direito. Assim, foi possível para os teóricos do Direito de Danos argumentarem a favor de que a Responsabilidade Civil é uma questão de como se fazer justiça diante dos danos, e não de como criar meios para o desestímulo e de controle dos acidentes, como pregava a Análise Econômica do Direito.

Neste sentido, seguimos o pensamento de Benjamin Zipursky:

It is no exaggeration to say that prior to Rawls's theory of justice, no one considered defining their theoretical aspirations in tort law in any way but in terms of the social ends of tort law. Rawls's assertion that "[j] ustice is the first virtue of social institutions" - backed up by a non-metaphysical and rigorous theory of justice - is undeniably a large part of the intellectual history behind the transformation that occurred, wherein scholars have now returned to the idea that theorists of tort law should ask the question: What does this area of the law have to do with justice? (ZIPURSKY, 2004, p. 1930-1931).

Assim, embora Rawls não tivesse como preocupação o Direito Privado e a Responsabilidade Civil, ou até a noção tradicional de Justiça Corretiva geralmente associada 
ao Direito Privado, sua teoria da justiça reavivou o interesse e a esperança na noção de justiça teoricamente formulada e, com isso, abriu espaço para um novo flanco de discussão sobre a Responsabilidade Civil no contexto anglo-saxão, este que acabou ganhando certa relevância por força da forte oposição ao novo momento que se estabelecia, que era a Análise Econômica do Direito. Até hoje, este grupo de teorias (teorias baseadas na justiça) segue sendo o principal grupo de contraposição às abordagens econômicas dentro da Filosofia da Responsabilidade Civil.

\section{A CONCEPÇÃO DE JUSTIÇA DE JOHN RAWLS}

Em 1971, John Rawls publica "Uma Teoria da Justiça" (RAWLS, 2016), obra que mudou o panorama da discussão sobre a justiça, propondo uma concepção de justiça que se apresentava como uma alternativa contra o Intuicionismo e, principalmente, o Utilitarismo. O foco da teoria rawlsiana é apresentar o que é a justiça em um contexto idealizado de sociedade, que corresponde à uma sociedade bem ordenada.

Como um liberal, Rawls defende que os indivíduos devem ser livres para perseguirem seus planos de vida, que refletem a concepção de bem que possuem. Parte do pressuposto de que não existe apenas uma concepção válida de bem, mas que é um fato de que existe um pluralismo de valores. Também parte do fato de que os recursos que os indivíduos têm a disposição para perseguirem seus planos de vida são escassos, havendo a necessidade de se estabelecer princípios para governar a distribuição justa destes recursos.

E como definir quais serão estes princípios? Como um liberal e pertencente à tradição moderna, Rawls define sua teoria em função dos indivíduos. Assim, para ele, os princípios que irão reger a distribuição dos recursos serão aqueles a que todos irão escolher e concordar. A ideia de um acordo a que os indivíduos devam chegar sobre os princípios de justiça reflete a noção de um contrato social. Mas como se conseguirá descobrir quais seriam estes princípios a que todos concordariam em aceitar?

Para isso, Rawls desenvolve um mecanismo hipotético chamado de posição original. Ele percebe que, no estabelecimento dos termos do acordo, os indivíduos levam consigo determinadas condições anteriores, como riqueza, valores, prestígio, etc., que acabam por afetar a sua capacidade negocial, dando-lhes maior ou menor poder de barganha sobre quais princípios serão adotados. Tais condições anteriores Rawls chama de Posição Social Relativa e uma de suas principais ideias é a criação de um mecanismo de neutralização dela.

Os sujeitos na Posição Original são postos sobre o que Rawls chama de "véu de ignorância", que funciona como um neutralizador epistêmico, fazendo com que os indi- 
víduos nesta posição não saibam a sua Posição Social Relativa. Assim, não sabem quem são, o quanto possuem de riqueza, o quanto podem herdar, quais as vantagens naturais possuem, etc., impedindo que o indivíduo seja parcial em favor de uma determinada posição que o beneficie.

Rawls afirma que, na posição original e sob o véu de ignorância, os indivíduos necessariamente escolheriam dois princípios de justiça:

Primeiro: cada pessoa deve ter um direito igual ao sistema mais extenso de iguais liberdades fundamentais, compatível com um sistema similar de liberdade para outras pessoas.

Segundo: as desigualdades sociais e econômicas devem estar dispostas de tal modo que (a) se possa razoavelmente esperar que se estabeleçam em benefício de todos como (b) estejam vinculadas a cargos e posições acessíveis a todos (RAWLS, 2016, p. 73).

O primeiro princípio Rawls denomina de princípio da liberdade igual, enquanto o segundo se divide em dois subprincípios: (a) corresponde ao princípio da diferença e (b) corresponde ao princípio da igualdade equitativa de oportunidades. Estes princípios se constituem como critérios que se aplicam à estrutura básica da sociedade. Também somente são aplicáveis a sociedades bem ordenadas, ou seja, em sociedades que buscam promover o bem de todos, nas quais estão presentes as circunstâncias da justiça - onde não exista extrema escassez ou abundância de bens, onde as pessoas são mais ou menos iguais entre si e onde elas sejam vulneráveis às agressões dos demais. Por fim, os princípios de justiça não se aplicam às relações entre indivíduos, mas às relações entre indivíduos e instituições.

Antes de finalizar nossa exposição, há uma tese rawlsiana melhor desenvolvida após "Uma Teoria da Justiça" que nos será especialmente relevante e por isso tomará um pouco mais da nossa atenção. Em "O Liberalismo Político", Rawls desenvolve a distinção entre pessoas razoáveis e pessoas racionais (RAWLS, 2000, p. 92-98), como ideias básicas facilmente distinguíveis através da forma como empregamos estes conceitos na linguagem corrente. Rawls compreende que o sujeito razoável possui duas características básicas, entendidas como virtudes das pessoas: ele está disposto a "propor princípios e critérios como termos eqüitativos de cooperação e a submeter-se voluntariamente a eles, dada a garantia de que os outros farão o mesmo" (RAWLS, 2000, p. 93). São indivíduos que querem se engajar em uma cooperação social equitativa, e por isso são elementos essenciais de uma ideia de sociedade como um sistema de cooperação, que Rawls já defendia desde "Uma Teoria da Justiça". Rawls assim descreve a atitude da pessoa razoável: 
Costumamos dizer que as pessoas razoáveis não são movidas pelo bem comum como tal, mas desejam, como um fim em si mesmo, um mundo social em que elas, em sua condição de livres e iguais, possam cooperar com as outras em termos que todos possam aceitar. Insistem em que a reciprocidade vigore nesse mundo, de modo que cada pessoa se beneficie juntamente com as outras (RAWLS, 2000, p. 93-94).

Ser movido por uma determinada concepção de bem é típico das pessoas racionais. São considerados racionais os agentes dotados de "capacidades de julgamento e deliberação ao buscar realizar fins e interesses peculiarmente seus" (RAWLS, 2000, p. 94). Sua racionalidade se manifesta na forma como estes fins e interesses são adotados e promovidos, bem como na forma como são priorizados e na escolha dos meios mais eficientes pelos quais eles se concretizarão.

O sujeito racional não é, porém, um egoísta puro. Ele pode perseguir fins e interesses que não beneficiem a ele próprio apenas, mas também a outras pessoas. $\mathrm{O}$ que o agente racional não têm é uma forma de sensibilidade moral que o faça querer se engajar em uma cooperação social e que o faça querer seguir os termos de uma cooperação que sejam razoáveis para que todos (ele e os outros), como iguais, aceitem.

Em suma, agimos de forma racional quando empregamos meios inteligentes para concretizar determinados fins e interesses pessoais. Por outro lado, agimos de forma razoável quando restringimos nossos fins e interesses pessoais em nome de princípios justos estabelecidos em um sistema de cooperação social. Tais noções são claramente distinguíveis, mas são complementares na concepção de justiça de Rawls. Afirma ele:

Como idéias complementares, nem o razoável nem o racional podem ficar um sem o outro. Agentes puramente razoáveis não teriam fins próprios que quisessem realizar por meio da cooperação eqüitativa; agentes puramente racionais carecem do senso de justiça e não conseguem reconhecer a validade independente das reivindicações de outros de outros (RAWLS, 2000, p. 96).

A concepção de pessoa aqui exposta por Rawls, portanto, pressupõe que os indivíduos sejam, ao mesmo tempo, razoáveis e racionais, no sentido de que se constituem como agentes interessados em perseguir seus próprios interesses e fins, mas também estão dispostos a limitar sua liberdade para persegui-los de acordo com certos termos que podem ser aceitos por todos em um esquema de cooperação. 


\section{TEORIAS CONTRATUALISTAS DA RESPONSABILIDADE CIVIL}

Em Rawls in Tort Theory: Themes and Counter Themes, Benjamin Zipursky apresenta cinco temas da teoria rawlsiana que tem inspirado os filósofos da Responsabilidade Civil. São eles: a) a situação de escolha prévia (na posição original) e a regra maximin; b) a metodologia construtivista kantiana; c) a ideia de equilíbrio reflexivo; d) a distinção entre razoabilidade e racionalidade; e) a ideia de que a justiça é a primeira virtude das instituições sociais (ZIPURSKY, 2004, p. 1923).

Tais ideias influenciaram, de formas distintas, teóricos como George P. Fletcher, Gregory C. Keating, Arthur Ripstein e John Oberdiek na defesa de uma teoria contratualista da Responsabilidade Civil. Tais temas não são abordados de forma uniforme entre as teorias, se misturando e dissociando em cada uma. Por isso não iremos expor cada um dos temas e explicar sua influência na construção teórica do Direito de Danos. Ao invés disto, nos limitaremos a expor a proposta teórica de Gregory C. Keating, considerado o maior defensor das teorias contratualistas no âmbito da Responsabilidade Civil, na qual a distinção rawlsiana entre razoabilidade e racionalidade e a ideia de cooperação social tem um papel central. Para isso, porém, é inevitável que tenhamos que abordar um pouco da teoria de George P. Fletcher em virtude da influência exercida sobre Keating. É o que passamos a fazer.

\subsection{Fletcher e o paradigma da reciprocidade}

Um ano depois da publicação de "Uma Teoria da Justiça" por John Rawls, George P. Fletcher publica o seu famoso artigo Fairness and Utility in Tort Theory (FLETCHER, 1972), com o projeto claro de se contrapor às teorias econômicas de fundamentação do Direito de Danos. A Análise Econômica do Direito aplicada à Responsabilidade Civil como teoria que, por exemplo, busca minimizar os custos dos acidentes, preocupa-se apenas com a riqueza e a situação do causador do dano, e não com a sua conduta (FLETCHER, 1972, p. 547). Figura, portanto, como um argumento baseado na justiça distributiva, deixando de lado um aspecto muito relevante na forma como se entende a Responsabilidade Civil, que é a Justiça Corretiva. Fletcher quer, portanto, apresentar uma proposta não-consequencialista, opondo-se à teoria econômica e defendendo uma abordagem mista, mesclando considerações de Justiça Distributiva e Corretiva.

Para se contrapor ao paradigma ditado pela Análise Econômica do Direito, que se baseia em um cálculo utilitário, Fletcher coloca no centro de sua abordagem um paradigma alternativo, que chama de paradigma da reciprocidade. Tal paradigma está baseado em um princípio de equidade - que também costuma ser chamado de princípio de 
reciprocidade - que surge a partir de uma analogia com o primeiro princípio de justiça de Rawls (princípio da liberdade igual) e determina que todos os indivíduos possuem direito a maior quantidade de segurança compatível com a segurança dos demais. Nas palavras de Fletcher:

All of these manifestations of the paradigm of reciprocity [...] express the same principle of fairness: all individuals in society have the right to roughly the same degree of security from risk. By analogy to John Rawls' first principle of justice, the principle might read: we all have the right to the maximum amount of security compatible with a like security for everyone else. (FLETCHER, 1972, p. 550).

Como podemos ver acima, a forma de apropriação da teoria rawlsiana na construção de Fletcher ainda é relativamente modesta. Ele desenvolve um princípio de reciprocidade em que todos devem possuir um grau igual de segurança dos riscos que se aproxima, por analogia, do primeiro princípio de justiça de Rawls, mas tal aproximação se dá apenas em forma. Todos os pressupostos rawlsianos que envolvem a escolha pelo primeiro princípio de justiça não estão presentes na argumentação, e podemos dizer que estão, de alguma forma, pressupostos nela somente porque Fletcher apela à noções como equidade ou igualdade.

Prossigamos na argumentação, pois ela nos será valiosa mais a frente. Este princípio de equidade opera sobre o Direito de Danos gerando uma divisão entre dois tipos de risco. Existem riscos recíprocos, em que um indivíduo, ao mesmo tempo que impõe risco a outros, também os suporta em mesma quantidade. Por outro lado, existem riscos não-recíprocos, em que, por exemplo, o indivíduo apenas suporta o risco, não o impondo aos demais, ou apenas o impõe, deixando com que os demais tenham que suportá-lo. Em uma partida de futebol, os jogadores comuns impõe e suportam os mesmos riscos de se acidentarem e contraírem lesões, sendo estes riscos recíprocos. Porém, se um jogador, por algum motivo, passa a desenvolver uma conduta agressiva, roubando bolas com violência e dando carrinhos sem motivo, passa a impor riscos aos demais jogadores que ele não suporta de forma igual. Estes riscos são não-recíprocos.

As atividades humanas não naturalmente perigosas. Fletcher afirma que, para desenvolver suas atividades, os indivíduos precisam impor riscos aos demais, e por isso também devem aceitar que os outros também imponham riscos. Os indivíduos possuem, portanto, direito a impor riscos que sejam recíprocos. Porém, se um indivíduo impor um risco não-recíproco e causar um dano, terá o dever de compensar. A Responsabilidade Civil, portanto, surge diante dos danos causados pela imposição de riscos não-recípro- 
cos por parte de um agente, ou seja, riscos que a vítima não esperaria de forma razoável.

O esquema apresentado serve para explicar tanto os casos de Responsabilidade Subjetiva quanto Objetiva. No caso do primeiro, a culpa é explicada como imposição irrazoável de riscos sobre os demais. É o caso do jogador raivoso que resolve intencionalmente elevar o nível dos riscos que impõe ao agir violentamente em campo. Existem, porém, ações que por si só impõe riscos maiores do que os normalmente impostos. É o exemplo da obra em um prédio, no qual o risco imposto pelo proprietário da obra de atingir transeuntes com certos materiais não se compara com os riscos que os transeuntes impõem sobre a obra. Neste caso claro de não-reciprocidade, o agente causador dos danos gerados por riscos não-recíprocos deve, portanto, compensar.

\subsection{Keating e a reciprocidade do dano}

Como dissemos, Gregory C. Keating é considerado o principal defensor das teorias contratualistas da Responsabilidade Civil (OBERDIEK, 2014, p. 106; ZAMORA, 2013 , p. 104). Passaremos a abordá-la para entender quais são as suas teses centrais e como elas se relacionam com a teoria rawlsiana. Comecemos pela primeira tarefa.

A teoria de Keating ${ }^{6}$ é um refinamento da proposta de Fletcher - por isso a importância de apresentá-la anteriormente -, mas que adentra mais fundo na teoria contratualista rawlsiana. Além do mais, Keating, diferentemente de Fletcher, não se baseia na Justiça Corretiva, mas propõe uma teoria baseada na Justiça Distributiva, em que o Direito de Danos pode ser entendido através da lógica da distribuição dos encargos dos acidentes.

Keating posiciona o Direito de Danos como parte dos termos equitativos estabelecidos pela cooperação social, realizada por indivíduos que são livres e iguais, e que agem de forma razoável e racional. Gastamos bastante tempo explicando a diferenciação, desenvolvida por Rawls em "O Liberalismo Político", entre o razoável e o racional e tal exposição nos será útil agora. Para Keating, o objetivo da Responsabilidade Civil é conciliar a liberdade dos indivíduos de desenvolver atividades que geram riscos, condição necessária para que possam perseguir seus interesses e fins - e, assim, agir racionalmente - visto que as atividades humanas geram riscos naturalmente, com a liberdade com relação aos danos que podem ser causados pelas atividades perigosas, ou seja, com a segurança contra danos a serem causados.

Keating se contrapõe a Fletcher negando a caracterização da Responsabilidade Civil

6 Keating possui diversos trabalhos em que busca aplicar o contratualismo rawlsiano no âmbito da Responsabilidade Civil, possuindo trabalhos que buscam fundamentar tanto a Responsabilidade Subjetiva quanto a Responsabilidade Objetiva de empresas. Em nossa exposição, adotaremos a sua proposta como exposta em Rawlsian Fairness and Regime Choice in the Law of Accidents (KEATING, 2004). 
a partir da reciprocidade do risco, substituindo-a pela reciprocidade do dano, entendido como ofensa à integridade física ou a morte. Para ele, maior atenção deve ser dada ao problema posterior relacionado ao dano do que ao problema anterior do risco, pois é da integridade física das pessoas - que o dano ofende - que um sistema de responsabilidade deve cuidar. Assim, retomando a tentativa de conciliação entre os dois tipos de liberdade (a liberdade de impor riscos e a segurança), Keating afirma que a segurança, como liberdade com relação ao dano, é mais importante que a liberdade de desenvolver condutas perigosas. Isto leva Keating a defender um regime de Responsabilidade Civil mais amplo do que o de Fletcher, ou seja, defender um regime de Responsabilidade Civil Objetiva que vise oferecer um elevado grau de segurança aos indivíduos.

Desta breve e apressada exposição da teoria de Keating, podemos perceber que as noções rawlsianas como a de cooperação social equitativa e o conceito normativo de pessoa como razoável e racional ${ }^{7}$ são muito caras à sua argumentação.

É possível afirmar também que Keating dá alguns passos a mais na apropriação da teoria de Rawls no âmbito do Direito de Danos, principalmente em comparação à Fletcher, mas estes passos não significam uma apropriação completa ou uma aplicação direta da teoria. Assim, a argumentação de Keating não deve ser considerada rawlsiana por seguir a mesma estrutura de pensamento ou método filosófico de Rawls, mas por estar permeada de argumentos e teses que podem ser remetidas a ele.

Por exemplo, Keating afirma que não está preocupado em fornecer uma teoria ideal nos moldes de Rawls (KEATING, 2004, p. 1868-1969), e por isso a ideia de indivíduos em uma posição original e sob um véu de ignorância tem que escolher sobre os princípios que orientarão seu sistema de responsabilização por danos não ocupa espaço em sua teoria.

Outro ponto de distanciamento com relação à Rawls é que Keating não está preocupado em fornecer um princípio que se aplique a todos, pois os princípios de distribuição dos custos dos acidentes não se aplicam efetivamente a todos os indivíduos (KEATING, 2004, p. 1873). A distribuição dos custos dos acidentes deve ocorrer entre aqueles que são beneficiados pelas atividades que causaram o acidente. A argumentação de Keating, assim, passa longe de se preocupar com a estrutura básica da sociedade, o que seria de se esperar de imediato quando se imagina a aplicação de uma teoria rawlsiana no âmbito de relações entre particulares.

7 Ainda sobre esta distinção, em outros trabalhos Keating define que a noção de racionalidade é a que está consagrada no raciocínio da Análise Econômica do Direito - leia-se na leitura de Richard Posner sobre a responsabilidade subjetiva como baseada na racionalidade econômica (ZIPURSKY, 2004, p. 1928). Tal visão seria errada porque desconhece as expectativas dos indivíduos e os requisitos da vida em comunidade. Propõe, então, uma teoria baseada na imposição razoável de riscos, ao invés de uma imposição racional (ZAMORA, 2013, p. 103). 


\title{
5 CONCLUSÃo
}

Longe de fazer uma defesa das teorias contratualistas e das abordagens rawlsianas da Responsabilidade Civil, a proposta deste artigo foi a de expor o contexto histórico e filosófico em que se desenvolveram e os delineamentos teóricos das principais teorias contratualistas, para podermos entender como Rawls influenciou na construção destas propostas.

As ideias de Contrato Social e Cooperação Social entre indivíduos razoáveis e racionais possuem um espaço importante nas argumentações, como esperamos ter demonstrado. Concluímos também que a influência de Rawls não é direta, pois sua metodologia, a ideia de colocar os indivíduos na posição original e sob um véu de ignorância, não se aplica às teorias contratualistas. Seria problemático promover uma apropriação direta da teoria de Rawls, pois esta se propõe apresentar a justiça dentro da estrutura básica da sociedade e na relação entre indivíduos e instituição, e não entre indivíduos e particulares.

Diante dessas questões, não resta claro se esta forma de apropriação de Rawls é adequada ou se sustenta no sentido de que se possa afirmar que constitui uma teoria rawlsiana da Responsabilidade Civil. Estas questões, porém, necessitariam de uma análise mais aprofundada do que a que desenvolvemos aqui. Independente disto, a importância histórica destas abordagens e papel delas na formatação de uma nova tradição de fundamentação do Direito de Danos são questões relevantes que buscamos deixar claras aqui. Embora as abordagens contratualistas não sejam as dominantes no âmbito da Filosofia da Responsabilidade Civil, o seu papel no quadro geral da disciplina é inegável, o que já justifica todo o esforço de estudos dessas abordagens.

\section{RAWLSIAN THEORY OF JUSTICE AND TORT LAW}

\begin{abstract}
This paper aims to discuss how the concept of justice developed by John Rawls influenced the Philosophy of Tort Law, based on contractualist theories George P. Fletcher and, especially, Gregory C. Keating. The work begins with a historical analysis of the Philosophy of Tort Law field, showing how Rawls, in reinvigorating the concept of justice, gave a new force to the view that basis Tort Law in the idea of justice. Then, exposes some important aspects of Rawls' theory of justice and after analyzes contractualist theories, exposing his central theses and the points that they use Rawlsian concepts.
\end{abstract}

Keywords: John Rawls; Tort Law; Philosophy; Justice. 


\section{REFERÊNCIAS}

FLETCHER, George P. Fairness and Utility in Tort Theory. Harvard Law Review, Cambridge, vol. 85, n. 3, p. 537-573, 1972.

GARGARELLA, Roberto. As teorias da justiça depois de Rawls: um breve manual de filosofia política. São Paulo: WMF Martins fontes, 2008.

KEATING, Gregory C. Rawlsian Fairness and Regime Choice in the Law of Accidents. Fordham Law Review, New York, vol. 72, issue 5, p. 1857-1921, 2004.

OBERDIEK, John. Structure and Justification in Contractualist Tort Theory. In: OBERDIEK, John (ed.). Philosophical Foundations of the Law of Torts. Oxford: Oxford University Press, 2014.

RAWLS, John. O Liberalismo Político. $2^{\mathrm{a}}$ ed. São Paulo: Editora Ática, 2000.

RAWLS, John. Uma Teoria da Justiça. $4^{\text {a }}$ ed. São Paulo: Martins Fontes, 2016.

ZAMORA, Jorge Fabra. Estado del arte de la filosofia de la responsabilidade extracontractual. In: PULIDO, Carlos Bernal; ZAMORA, Jorge Fabra (eds.). La Filosofía de la Responsabilidad Civil: estúdios sobre los fundamentos filosófico-jurídicos de la Responsabilidad Civil Extracontractual. Bogotá: Universidad Externado de Colombia, 2013.

ZANITELLI, Leandro M. Strict Liability and the Fair Level of Damages. Economic Analysis of Law Review, Brasília, vol. 1, n. 1, p. 78-94, 2010.

ZIPURSKY, Benjamin C. Rawls in Tort Theory: Themes and Counter Themes. Fordham Law Review, New York, vol. 72, issue 5, p. 1923-1940, 2004. 